\section{Creating Collaborative Schools in the United States: A Review of Best Practices}

\author{
Caitlin J. Solone ${ }^{\mathrm{a}}$, Bryan E. Thornton ${ }^{\mathrm{b}}$, Jenny C. Chiappec, \\ Crystal Perez ${ }^{d}$, Molly K. Rearicke, Mary A. Falvey ${ }^{f}$
}

\begin{tabular}{ll}
\hline Received: & 28 September 2019 \\
Revised: $\quad 21$ November 2019 \\
Accepted: $\quad 30$ December 2019 \\
ISSN: 1307-9298 \\
Copyright $\odot$ IEJEE \\
www.iejee.com
\end{tabular}

DOI: 10.26822/iejee.2020358222

\begin{abstract}
Collaboration is considered an essential characteristic for inclusive education to be effective and reflective of research-based best practices. General and special education teachers and related service personnel must work together and share goals, strategies, and physical space for students with and without disabilities to learn in inclusive settings. Teachers and parents must build trusting and collaborative partnerships in the delivery of inclusive education. Finally, students with and without disabilities must work together and support one another in building effective schools. We offer research-based strategies for and examples of effective collaborative relationships and outcomes from those relationships.
\end{abstract}

Keywords: Collaboration, Co-Teaching, Collaborative Learning, Collaborative Teaching, Collaborative Practices, Inclusive Education, Inclusion, Special Education

\section{Introduction}

In the United States, students with eligible disabilities who attend schools that receive federal funding are entitled to a "free and appropriate public education," or FAPE (U.S. Department of Education, 2010). If the nature of the disability impedes the student's ability to learn and make progress in general education, the student may be eligible for special education services and supports. Special education services may include many components including specially designed instruction, therapeutic services such as speech therapy, occupational therapy, physical therapy, classroom accommodations, assistive technology devices, one-on-one assistants, and more. For students receiving these services, an Individualized Education Program (IEP) is required by law and outlines the specially designed, individualized program the school must provide the student. This program is reviewed and updated annually by the student's IEP team. This team includes the parents or guardians, the student, general and special education teachers, an administrator such as a school principal, and any service providers the student requires to make meaningful academic gains each year. The multidisciplinary approach inherent in special education elicits the need for effective collaboration amongst IEP team members to provide the most comprehensive and cohesive program possible. Throughout this article, a review of existing literature and several vignettes based on true events will be used to illustrate the need for, challenges of, and evidence-based solutions to promote effective collaboration amongst IEP team members.

\section{The Need for Collaboration}

Sebastian is a 5-year-old boy with Down syndrome who had successfully attended and completed an integrated preschool program for students with and without disabilities taught by qualified teachers in California. Upon completion of his preschool program at the age of 5, the school district recommended he be placed in a segregated self-contained classroom for students in kindergarten to second grade with moderate to severe disabilities for $78 \%$ of his school day. Despite the fact Sebastian's family, his attorney, and expert witnesses strongly objected to this placement. The school district and the family were at odds and unable to come to a collaborative consensus. The family eventually decided to file for due process, which would allow an impartial judge to render a decision about what was best for Sebastian. The family firmly believed his growth in communication skills, social pragmatics, knowledge of grade-level curriculum, and ultimately his ability to function in society would be severely curtailed if he was forced into a segregated special education class for the majority of his school day. The school district's contention was, for him to make progress on his IEP goals, Sebastian needed to attend a segregated self-contained classroom for $78 \%$ of the day. The parents were met with no opportunity to collaborate with the IEP team on this matter and no room for further discussion or problem solving.

Creating and establishing opportunities for people with and without disabilities to engage and learn with and from each other is essential for building communities that work for everyone (O'Brien \& Mount, 2015). Historically, people with disabilities, like Sebastian, have had to endure rejection and forced segregation within society. In spite of U.S. litigation and legislation intended to eliminate such rejection and discrimination, tragically large numbers of people with disabilities continue to live, work, and go to school in segregated, isolated settings that often lead to lives of loneliness, diminished self-worth, and a sense of disempowerment (Falvey, 2005; National Council on Disability, 2018). Though individuals are still met with resistance around inclusive efforts today, many American schools and districts are moving toward more inclusive practices, spurring a great need for more intentional and effective collaboration techniques and practices.

\section{Inclusion}

For the past 40 years, researchers have conducted efficacy studies on inclusive versus segregated schooling for students

aCaitlin J. Solone, California State University, Los Angeles and University of California, Los Angeles, USA. E-mail: csolone@ucla.edu 'Bryan E. Thornton, California State University, Los Angeles and University of California, Los Angeles, USA. E-mail: bethornton1@gmail.com Jenny C. Chiappe, California State University, Dominguez Hills, USA. E-mail: jchiappe@csudh.edu

dCrystal Perez, Los Angeles Unified School District, USA. E-mail: cmp1803@lausd.net

eMolly K. Rearick, IGNITE Collective Inc., USA. E-mail: molly@ignitefutures.org

fCorresponding Author: Mary A. Falvey, Charter College of Education, California State University, Los Angeles. California, USA. E-mail: Mfalvey@calstatela.edu

(c) 2020 Published by T\& K Academic. This is an open access article under the CC BY- NC- ND license. (https://creativecommons.org/licenses/by/4.0/) 
with disabilities in the United States (Kalambouka, Farrell, Dyson, \& Kaplan, 2007; Lipsky \& Gardner, 1989; Morningstar, Shogren, Lee, \& Born, 2015). These research findings have concluded time and time again that inclusive education is more effective for both students with and without disabilities (Kurth, Mastergeorge, \& Paschall, 2016; Morningstar, Kurth, \& Johnson, 2017). This research has provided educators, parents, students, and litigators with evidence that inclusive classrooms are the research-based best practice placements for students with and without disabilities.

When parents and students are at odds with a school district's decisions, working through differences collaboratively can result in mutually agreed upon decisions. Unfortunately, in the case of Sebastian, that did not occur. Sebastian's parents sought legal council and his case was taken to due process, a legal right afforded to parents under the Individuals with Disabilities Education Act (IDEA; 2004). After several months, a decision was made. The court ordered the school district to provide Sebastian with a general education kindergarten placement with an inclusion specialist and a parent-approved behavior analyst to support Sebastian's learning. The district was also required to pay the cost of the above services and the legal fees the family had incurred throughout the process. In addition, the school district had to pay for their own legal fees. The school district's extraordinary expenses could have been avoided if the district had worked with the family and offered services that reflected research-based best practices-that is, inclusive education with individualized supports and services. Collaborative decision making that utilizes research-based best practices is both economical and socially just and can make a substantial difference to not only students with disabilities and their families, but also to the educational system and society at large.

Inclusive schools and communities are essential if we are to create a world that truly works for everyone. To create such a world, individuals with disabilities need to be the focus and emphasis of the opportunities and services provided. Unfortunately, when students with disabilities are assessed and identified as needing special education services, their deficits are too often the focus. Special education inherently utilizes student deficits as the justification for individualized supports, and while this is an essential component of identifying support needs, opportunities and expectations can too often be limited by ableist beliefs.

Education often aligns with a medical model of disability, which suggests that disabilities should be "fixed", "changed", or "cured" by professionals, treatments, or interventions. The social model of disability, on the other hand, posits that disabilities are socially constructed by way of the physical, structural, and attitudinal barriers within society, and it is society that must change to accommodate diverse individuals (Owens, 2015). To break down barriers that have historically resulted in segregation and isolation for students with disabilities, schools should adopt the social model of disability and begin to dismantle old systems and structures that disable students and instead provide the supports and services need ed to accommodate all learners. In truly inclusive schools, everyone shares the same purpose, albeit sometimes with different methods for achieving those purposes. In other words all means all (Shogren, McCart, Lyon, \& Sailor, 2015,) when referring to inclusive education.

Inclusion occurs when every individual at a school is in their age-appropriate classroom working on the same curriculum and content with access to individualized accommodations, modifications, services, and supports as needed. The Schoolwide Integrated Framework for Transformation (SWIFT) Center located at the University of Kansas is a powerful resource that supports inclusion and education reform at the state and district level. They outline key elements of inclusive schools which include inclusive academic and behavioral in- struction, a strong and positive school culture, trusting family and community partnerships, and collaboration. Inclusive classrooms are crafted using research-based practices such as: (a) peer-tutoring, (b) co-teaching, (c) strong instructional practices, (d) accommodations and modifications, (e) collaboration, and (f) democratic environments that support all students' learning and participation (Lindsey, Thousand, Jew, \& Piowlski, 2018; Mastropieri \& Scruggs, 2001).

Successful schooling and community-based services begin with the presence of strong collaborative relationships and partnerships. Effective communication among professionals and family members, including the person with a disability, is essential. Everyone benefits from a culture of working together when designing and implementing educational and community-based services and supports for people with and without disabilities. Collaboration, then, is at the heart of successful inclusion.

\section{Defining Collaboration}

Collaboration refers to people working together toward common goals and entails individuals with disabilities themselves, professionals, family members, community members, and friends coming together to work toward and achieve a shared vision. Individuals on collaborative teams have varied life perspectives and experiences and can add a great deal to the collaborative planning process. To become a collaborative team, the members of the team must share resources, expertise, perspectives, and responsibilities to create inclusive, effective, and meaningful programs and services for students with and without disabilities. Collaboration is about bringing individuals together in such a way that each member of the team agrees to use their heart (e.g., their character and intentions), their head (e.g., their beliefs and attitudes), and their hands (e.g., their actions and their approaches), to create a clear sense of purpose, values, and goals (Blanchard, Ripley, \& Parisi-Carew, 2015).

Collaboration does not mean avoiding confrontation. On the contrary, collaboration provides a vehicle for discussing difficult concepts and reflecting on various beliefs, attitudes, strategies, and ideas to build new perspectives. Collaboration does not force members of the collaborative team to arrive at a consensus. Sometimes it means individuals do not get their own way, but rather feel they can live with the collective decision made by the team, albeit after having had the opportunity for all team members to express their opinions and provide input. Collaboration is not a lack of individual accountability; rather it is best achieved when there are varied opinions. This entails each member of the collaborative team truly listening to each other, and collectively creating a shared vision. Collaboration is a commitment to a culture of mutual respect and trust, ultimately serving as a catalyst toward optimal student outcomes.

\section{Characteristics of Collaboration}

Much has been written about the numerous characteristics and essential elements of collaboration. Sometimes team members may feel forced to work together; however, when people work together and create a collaborative structure, the work runs more smoothly, is divided more evenly, and often results in improved outcomes for students. Collaboration, at a minimum, requires all team members commit to working together toward a common goal, which is how best to support students (Friend \& Cook, 2013). IEP team members as required under IDEA, consist of teachers (both special and general education), administrator, parents, students, and when appropriate, related service personnel, psychologists (as needed), and others who can contribute to building an educational program for a student with a disability. 
Parity

Collaboration requires parity among team members. Each person's contribution must be viewed as equally valued, and each person must be given equal power in the decision-making process. Collaboration must be based upon a commitment that all participants are important, listened to, and respected (Friend \& Cook, 2013). Achieving parity or equal status can prove difficult when the dynamic of those involved has created or embraced a culture of "us and them." It is essential for schools and families to break away from this type of mentality for there to be parity among all team members, including students and their families.

\section{Mutual goals}

Collaboration is based upon establishing mutual goals among team members. Team members do not have to share all their individual goals to collaborate, but it is necessary they have a shared vision and goals for the collaborative team meeting (Blanchard et al., 2015). For example, IEP team members must agree that the education of the student in focus is the central purpose of the meeting. In addition, the outcome for all team members should be to develop an appropriate educational program for that student, with significant input, insight, and wisdom from all team members. Members of the team must keep the student as the focus of the meeting or collaboration and not their individual or collective egos.

Shared responsibility for participation and decision making. Collaboration depends on shared responsibility for participation and decision-making. Collaborators must assume the responsibility of actively engaging in decision-making processes and ensure all stakeholders have the opportunity to do so as well. Effective collaboration embraces the unique perspectives of all team members and requires a sense of trust and shared responsibility (Friend \& Cook, 2013). A reminder may be needed that the student and their parents are essential members of the team and must be given respect and encouragement to be engaged in all decision making.

\section{Shared resources}

Individuals who collaborate share resources with each other. Sharing resources of time, knowledge, and materials can enhance the sense of ownership and creativity among team members. No member of the team should be disadvantaged due to a lack of resources, materials, or specialized knowledge. Parents of students with disabilities and students themselves are sometimes disadvantaged in IEP meetings because they are not always familiar with the jargon, limitations, or available options. Educators must be cognizant of this possible disadvantage and make every effort to provide parents and students with the necessary information and resources so they can contribute in making informed recommendations (Blanchard et al., 2015).

\section{Shared responsibility for outcomes}

Individuals who collaborate share responsibility for outcomes. Whether the results of collaboration are positive or negative, all participating individuals are responsible for what comes to pass and must work toward agreed upon components of the plan with fidelity and integrity to the best of their ability (Friend \& Cook, 2013). With shared responsibility comes shared accountability and the need for collaborators to not only hold themselves and each other accountable for adhering to the agreed upon commitments, but also to ensure the commitments are practical and the workload is delegated in an equitable way. Issues can arise when team members are expected to execute unrealistic goals due to time constraints, limitations in expertise, or other factors.
It is essential to be conscientious of each team member's workload and availability for additional work so agreements can be executed with fidelity and all team member can feel successful.

The major purpose of collaboration is to create change and to build new and improved educational opportunities for students and ultimately for schools. Collaboration among the various stakeholders, including teachers, students, families, school personnel, and administrators can be used to effectively transform schools, community agencies, and opportunities for individuals with and without disabilities to experience better outcomes.

\section{Synergy}

Collaboration offers the opportunity to experience synergistic ideas and perspectives. Synergy is the creation of a whole that is greater than the sum of its parts. Synergy is evident when problem solving results in solutions no one individual necessarily owns or is committed to; rather, team members share their ideas in such ways that new ideas and concepts emerge. Team collaboration is a key ingredient in delivering effective and high-quality services in schools. This relies on collaborative relationships in which team members work together in a seamless manner toward shared goals and subsequently develop strategies to carry out actions and remain accountable (King-Sears, Janney, \& Snell, 2015). In the following sections, specific strategies for effective collaboration among educators, parents, and students are discussed.

\section{Collaboration Between General and Special Educators and Service Providers}

Collaboration among educators and related service personnel is vital to the success of students with disabilities. General and special education teachers and related service providers receive highly specified training in their respective domains giving them a wealth of knowledge to use to meet the needs of the students they serve. When their expertise is shared amongst one another, the opportunities for students to make educational gains improves dramatically (Murawski \& Spencer, 2012). Historically, however, teacher education programs and specialist training programs have limited or nonexistent opportunities for educational personnel to learn, plan, and collaborate together (Delano, Keefe, \& Perner, 2008). Training delivered separately may beget a siloed service delivery system, unless systematic and strategic practices around collaboration are in place.

When one or more of the collaborative characteristics are missing, common pitfalls may arise. For example, one study conducted in the United States examined collaboration between special and general education teachers. Several special education teachers expressed feeling they lacked authority and were underused when working in a general education classroom (Conderman, 2018). One effective strategy to overcome this sense of feeling undervalued or underutilized is for general and special education teachers to co-plan and co-teach together (Murawski \& Hughes, 2010). Being seen as equals by students and one another is important and can be achieved when teachers work collaboratively to co-plan lessons, share preparatory responsibilities, and co-teach.

Co-teaching is defined as two or more educators coming together to plan and teach with a heterogeneous group of students in a general education classroom (Beninghof, 2012; Friend, Cook, Hurley-Chamberlain, \& Shamberger, 2010). When implemented effectively, co-teaching has repeatedly been shown to yield advantageous academic and social results for students with and without disabilities (McDuffie, Mastropieri, \& Scruggs, 2009; Murawski, 2006) and has proven particularly beneficial for students in the areas of 
reading and writing (Tremblay, 2013). Additionally, co-taught classrooms have a greater focus on social skills instruction and result in building stronger classroom communities (Murawski, 2006; Walther-Thomas, 1997; Weichel, 2001).

In addition to collaboration among teachers, it is essential teachers effectively collaborate with related service personnel (e.g., occupational therapists, speech and language pathologists, adapted physical education teachers). Section 300.34 of IDEA (2004), a federal law, defines "related services" as "supportive services as required to assist a child with a disability to benefit from special education". The role of the related service provider may differ based on the type and extent of the services required. Related service providers may work at more than one school and, depending on the specific student, their service delivery models are likely to vary. For instance, for some students, service providers may offer teachers suggestions and strategies through a consultative service delivery model, services may be provided inside the students' classroom or services may be implemented outside of the classroom in a one-on-one or small group setting. Similar to general and special education teachers, related service providers should allot time to collaborate and plan with teachers and can also engage in co-teaching to successfully incorporate and embed the strategies they have delineated within their instruction.

Students with significant support needs similar to Sebastian often have many adults working in different capacities to support various aspects of their education. Special and general education teachers, occupational therapists, speech and language therapists, adapted physical education teachers, counselors, and other specialists simultaneously serve students to ensure each student receiving special education services can derive meaningful benefit from their educational program each school year, a requirement mandated by a recent U.S. Supreme Court ruling in Endrew F. v. Douglas County School District (2017). Traditionally, IEP team members come together once per year at the annual IEP meeting to discuss a student's progress, needs, and future goals after which members of the team may go back to siloed existences, working in isolation from one another (Murawski \& Spencer, 2012). While collaborative practices can and do happen naturally in some cases, consistent ongoing collaboration is an essential ingredient for successful learning outcomes, or deriving meaningful benefit from their educational program.

There are many ways teachers can collaborate. One way is through collaborative curricular planning. Because all teachers engage in curricular planning, this is a natural time for special and general educators to collaborate. Teachers and related service providers must decide on when, where, and how often they will meet to ensure ongoing collaboration and coordination of student services. For collaboration to work, teachers must establish an open system of communication that allows all parties to reach out to one another via email, text message, or other means of communication, while also being respectful of each collaborator's time. Ideally, general education teachers will share their lesson plans with the special education teacher so the special education teacher can, in turn, prepare accommodations and modifications a student with a disability may need or from which they might benefit. In this scenario, the general education teacher comes prepared with weekly plans, while the special education teacher comes prepared with a deep knowledge of a student's IEP goals, services, and supports, and expertise about required accommodations, modifications, and interventions. Having structured agendas can be another helpful strategy to ensure efficiency since time is likely to be limited. One team member can serve as a timekeeper to make sure the meeting moves along at a pace that will allow them to complete the meeting having fully addressed the outlined agenda. Special education teachers can provide support in offering ideas for curricular adaptations for students with and without disabilities, ensuring a student's IEP goals are addressed throughout the day, and preparing lesson plans accessible to all learners.

Teams can also collaborate informally. In addition to holding weekly planning meetings, special and general education teachers can arrange to eat lunch together to discuss students' educational needs and progress. Both should agree neither has all of the answers and should remain open to each other's input. Together, a team of educators and related service personnel are able to provide a comprehensive and well-rounded educational program for each student and their classmates who might also be struggling to learn a particular concept or skill.

Despite the academic (Murawski, 2006) and social (Weichel, 2001) benefits collaboration can yield, perceptions of collaboration vary widely (Hagelman, 2013). Educators often express a myriad of concerns relating to collaboration, including: (a) lack of adequate planning time, (b) differing values and beliefs, and (c) a lack of collaborative efficiency (Carter, Prater, Jackson, \& Marchant, 2010).

Each team member comes with a different background, training, norms, perspectives, life experiences, and circumstances that all interact to shape the way each unique person sees the world, their place in it, and the best way to serve students. At times, these attributes may be at odds with one another. Individual team members must be committed to building and maintaining a culture of trust rather than resistance, respect for multiple perspectives, and a willingness to collaboratively problem solve.

When team members embrace each other's perspectives, stakeholders can be part of a team without feeling judged, inferior, or like their time is wasted. They are valued, voices are heard, and qualms can be expressed without fear. This allows individuals to contribute meaningfully and to the best of their capacity. Additionally, when individuals work in cultures where there is trust, they tend to express greater job satisfaction, a stronger alignment with the stated mission of the team or organization, a closer connection to their colleagues, increased empathy for their co-workers, and reduced burnout (Zak, 2017). With the benefits of collaboration being mutually beneficial to adults and students alike, greater emphasis on building and maintaining collaborative teams has the potential to shift education in ways that promote sustainability and improve achievement.

\section{Collaboration Between Parents and Teachers}

According to Erwin, Shogren, Soodak, Turnbull, and Turnbull (2011) a robust research-based literature demonstrates parent-teacher collaborative relationships as imperative for successful academic, behavioral, and social improvement of students with disabilities. Many parents feel unwelcome and uncomfortable participating in their children's education (Fish, 2006). While some schools have made efforts to comply with federal and state policies to meet the needs of students who receive special education services, this is not always the case (Larios \& Zetlin, 2006; Scorgie, 2015).

IDEA includes parent involvement as a key requirement in the creation of documents such as the IEP, which is a blueprint for the delivery of educational services for students with disabilities (Fish, 2006). Parents oftentimes experience a sense of powerlessness in IEP meetings. These feelings can often negatively impact parents who may already be faced with stressors such as feeling ill equipped to raise a child with a disability. This can challenge their parenting and can impact their self-confidence.

The United States is made up of a diverse population of many different ethnicities, languages, and cultures. Research with 
culturally and linguistically diverse (CLD) families has provided some important insight and directives for educators in terms of including and welcoming parents as collaborators and co-creators of students' educational programs. In a qualitative study with young Latina mothers of children with autism, Perez (2017) found these mothers felt special education professionals need to work on improving the quality, consistency, and tactful approaches in collaboration with them. Similarly, Fish (2006) found many parents feel illequipped to attend to the educational needs of their children and feel unprepared to respond to special education jargon. Perez (2017) discovered much of the information in written documents for parents, whether in English and Spanish, employed jargon and did not contain terminology commonly understood or defined.

Special education documents are full of discipline specific concepts, terminology, and acronyms, making it challenging for people who have not had similar training or extensive experience in special education to understand them. In addition, Perez (2017) found CLD families felt a disconnect with special education professionals because of their cultural background. Sometimes CLD families felt they should not question professionals, as this can be seen as a form of disrespect in their culture (Kalyanpur, Harry, \& Skrtic, 2000). Families who have a low socioeconomic status may also struggle with collaboration and experience an imbalance of power with educational professionals (Conroy, 2012). In some cases, parents of children with disabilities face many obstacles due to both a lack of resources known or available to them and limited knowledge about their children's disabilities. Financial strain on a family can exasperate these challenges and other challenges that interfere with establishing collaborative partnerships.

Harry (1992) shared, while it is true some parents may not particularly want to participate in their children's IEP, it is vital parents be sufficiently informed to elect their level of participation, make informed decisions, and give meaningful consent. Parents sometimes feel undervalued, intimidated, and judged by professionals. Perez (2017) revealed that, many times, parents of children with disabilities are misunderstood and misjudged by educational professionals, adding to the failure to effectively collaborate with parents.

It is important to recognize collaborative, active, equitable, and meaningful participation of parents of children with disabilities in their children's education as an imperative factor that needs to be addressed. Based upon her research, Perez (2017) recommends CLD parents become more outspoken about their concerns with educational professionals without hesitation or fear of being disregarded. Also, the responsi- bility of listening with empathetic intentions and purposeful responsiveness toward CLD parents falls upon the school districts and educators. Turnbull et al. (2011) emphasize that, just like one's own background influences what we value, how we think, and how we behave, each family will also be influenced by their cultural background and their foundational values. According to Falvey (2005), both educators and parents may have histories of difficult relationships. The author emphasizes the importance of letting go of the past and moving forward to collaboratively resolve problems and create opportunities and futures for students with disabilities.

Research surrounding family-educator collaboration is plentiful, and includes several common themes related to best practices. These are: (a) communication, (b) equity, (c) trust, and (d) respect (Blue-Banning, Summers, Frankland, Lord Nelson, \& Beegle, 2004; Scorgie, 2015; Staples \& Diliberto, 2010; Sucuoğlu \& Bakkaloğlu, 2018; Trainor, 2010; Valle, 2011; Zaretsky, 2004). Blue-Banning et al. (2004) described best practices for family-educator collaboration as "common sense and ordinary human decency" (p. 181). To address cultural and community differences, discussion of the following points must occur within each school setting.

Lucy's story is an example of how collaboration made an enormous difference in the quality and effectiveness of a student's inclusive education. Lucy began her public-school experience in a segregated special education class in a suburban school in California. As a kindergartner, she was eligible for special education services due to autism and expressive language delays, and her parents believed she would be better served in an inclusive setting. Lucy prospers when interacting with her older brother, children in their neighborhood, and other members of her community.

When Lucy's parents petitioned the school district that their daughter be fully included, they were categorically denied. Lucy's general education kindergarten teacher worked with the family and their advocate to include Lucy, who initially was placed in her classroom for 20 to 30 minutes each day. In this new environment, Lucy gained social skills such as following routines, and academic skills such as learning letters and numbers. She interacted with her classmates while learning grade-level material, and the general and special education teachers shared positive reports of her success.

When Lucy's parents called a team meeting to request full inclusion for first grade, Lucy's general education kindergarten teacher was her strongest advocate. In part as a result of this advocacy, the school district agreed to place Lucy in an inclusive first grade classroom. Recently, Lucy began her

Table 1. Best Practices for Educators

\begin{tabular}{|c|c|}
\hline Theme & Best Practices for Educators \\
\hline Communication & $\begin{array}{l}\text { - Focus on quality and quantity (consider frequency, purpose, and content) } \\
\text { - Communicate in a timely manner } \\
\text { - Be honest and open } \\
\text { - Include positive comments along with negative ones } \\
\text { - Use communication methods that work for each family (e.g., phone calls, emails, in person) } \\
\text { - Avoid jargon }\end{array}$ \\
\hline Equity & $\begin{array}{l}\text { - Acknowledge families as experts on their children } \\
\text { - Be willing to learn and to admit when you do not have an answer or a skill } \\
\text { - Work as a team to develop goals and solutions-engage in shared decision making } \\
\text { - Maintain awareness of perceived power and authority }\end{array}$ \\
\hline Trust & $\begin{array}{l}\text { - Be reliable } \\
\text { - Show you care for students } \\
\text { - Use discretion with private or sensitive information }\end{array}$ \\
\hline Respect & $\begin{array}{l}\text { - Honor each family's language, ethnicity, culture, etc. } \\
\text { - Be aware of families' other commitments } \\
\text { - Set high expectations for students } \\
\text { - Treat students as people } \\
\text { - Be on time }\end{array}$ \\
\hline
\end{tabular}


second-grade year, fully included, and continues to make documented progress with the support of her parents, teachers, and other support staff. Ongoing collaboration between her parents and teachers is key to facilitating her success. Lucy's story offers one example of how collaboration between parents and educators can make a significant difference in a student's life.

\section{Collaboration Between Students With and Without Disa- bilities}

Research on elementary-age students' understandings of race and socioeconomic status (SES) have repeatedly highlighted the malleability of student thinking about social identities (Cameron \& Rutland, 2008). Over the last two decades, an emerging literature has expanded on this to consider schoolage children's beliefs about disability as well. Several studies conducted in the United States have documented existing biases in school-age children's attitudes toward students with disabilities, suggesting children without disabilities tend to express social preference for their classmates without disabilities as compared to those with physical or intellectual disabilities (Nowicki \& Sandieson, 2002). However, research has shown attitudinal and behavioral changes can occur as a result of both education (often in the form of ability awareness training) and contact. These changes in attitude and behavior can occur, in part, due to a recognition of shared similarities between students with and without disabilities (de Boer, Pijl, \& Minnaert, 2012; Rillotta \& Nettelbeck, 2007). Clearly, contact between students has the potential to increase the social ac ceptance of students with disabilities by their peers without disabilities. This has served as one of the cornerstone arguments in favor of inclusion and collaboration.

Proponents of inclusive education claim having students with disabilities attend their neighborhood schools in general edu cation classrooms results in increased opportunities for their social participation (United Nations, 2006). Evidence supports these claims, suggesting not only does increased contact between students with and without disabilities lead to better social outcomes for students with disabilities, but also similar benefits can be reported for youth without disabilities as well. Inclusion and student-to-student collaboration has been associated repeatedly with increased tolerance and empathy and the development of meaningful cross-ability friendships. How ever, Pijl (2005) noted physical inclusion alone does not necessarily result in such benefits. In a a review of the literature on the effects of inclusive education on students' attitudes toward peers with disabilities, several studies demonstrated inclusive education was associated with a negative effect on student attitudes (de Boer, Phil, \& Minnert, 2017) Having students with and without disabilities merely share space is not always enough to effect change. It is essential to consider how students share space and to examine the roles of teachers in facilitating this process. Social psychological research offers one way of thinking about how students might share space.

\section{Intergroup Contact}

In The Nature of Prejudice, U.S. social psychologist Floyd Allport (1954) laid out a highly influential theory on intergroup contact, which demonstrated the positive effects of contact between members of different social groups. In Allport's estimation, mere exposure between groups could reduce prejudice. While Allport's work focused primarily on different racial and ethnic groups, subsequent researchers have demonstrated similar effects in relation to sexual orientation, mental illness, and disability.Yet researchers, including Allport himself, have acknowledged the limits of mere exposure, noting cases in which contrasting effects of intergroup contact were demonstrated. In some cases, exposure actually exacerbated prejudice, which perhaps helps to explain the divergent studies included in de Boer and Minnaert's (2012) review of the literature on inclusion and student attitudes. In offering an explanation for conflicting findings on intergroup contact, Allport posited four ideal features or positive factors that could influence intergroup contact in a way in which prejudice would be more likely to decrease.: (a) equal status of the groups in the situation, (b) common goals, (c) intergroup cooperation and collaboration, and (d) the support of authorities, law, or custom. All four of these positive factors hold implications for teachers in terms of designing an inclusive environment that moves beyond tolerance and fosters values such as acceptance and appreciation.

\section{Cooperative Learning}

Cooperative learning offers an evidenced-base activity that can increase meaningful learning for all students and also move beyond mere space sharing (Thousand, Villa, \& Nevin, 2002; Villa, Thousand, \& Nevin, 2010). More specifically, cooperative learning has the potential to embody all four of Allport's positive factors. Cooperative learning, in its many forms, requires students to work together at an activity to achieve common goals Johnson \& Johnson, 1975, 1989; Kagan, 1992; Slavin, 1983, 1990). It is important to ask, however, "What types of attitudes are being passed on in the implementation of cooperative learning?" While Murray (2002) reviewed the theoretical basis underpinning cooperative learning, many teachers may follow the basic protocol of cooperative learning activities without asking essential questions such as, "Are all students participating in meaningful ways?" or, "What are the implications of or philosophy behind how I am facilitating this process?"

In a sense, teachers, classrooms, and the overall culture of the school act as the support of authorities, laws, and customs, while common goals and intergroup cooperation are embedded within the framework of cooperative learning. Allport (1954) refers this as equal status of the groups in the situation. Teachers have a responsibility to design and guide cooperative learning activities in a way that promotes equal status among groups. This does not mean all students are always treated or educated in exactly the same manner. Rather all students should be treated with and afforded the same dignity and respect while providing equal opportunities for success. Appropriate accommodations and modifications should be made available to students with and without disabilities to ensure meaningful participation in learning activities. In doing this, general and special education teachers must challenge or subvert any tendencies on the part of the students or themselves toward paternalism, charity, or pity and avoid sending the message that the job of general education students is to help students with disabilities. Cooperative learning is not a one-way street. Ultimately, students with disabilities must be given the opportunity to demonstrate reciprocity and to contribute in meaningful ways to their classroom and with their classmates. The attitudes and spirit in which cooperative learning, specifically, and inclusion, more generally, are undertaken are key.

Physician Rachel Remen (1999), a leading medical educator, therapist, and teacher in the United States has distinguished between attitudes of helping, serving, and fixing. She wrote:

Helping, fixing and serving represent three different ways of seeing life. When you help, you see life as weak. When you fix, you see life as broken. When you serve, you see life as whole. ... Serving is different from helping. Helping is not a relationship between equals. A helper may see others as weaker than they are, needier than they are, and people often feel this inequality. The danger in helping is that we may inadvertently take away from people more than we could ever give them; we may diminish their self-esteem, their sense of worth, integrity or even wholeness. (p. 1)

As facilitators of collaboration, teachers should reflect on how their own beliefs and, potentially, biases inform the way they 
design and lead cooperative learning and other collaborative activities. Cooperative learning offers tremendous potential for inclusion. However, the philosophies and attitudes undergirding the approach must also be taken into consideration-common goals, intergroup cooperation, meaningful contributions, equal status of group members, and the support of persons in positions of authority.

Classrooms and schools frequently employ a tutor and tutee approach, arising out of a cognitive science perspective (Murray, 2002), between students with and without disabilities. However, to build a collaborative relationship between students, each student, regardless of their ability, should have an opportunity to be a leader and contributing member to their group and classroom. To make this a reality, students with and without disabilities must comprehend and contribute to how they are contributing members. Cooperative learning opportunities provide for self-evaluation, which can teach students to be self-determined at a young age to be better prepared for the transition into adulthood. A first step is to invite and welcome students with disabilities as members of their IEP team. Unfortunately, students with disabilities often sit in their own IEP meetings unaware of how to be an active participant. They may need to be taught skills related to active participation. To do this, active engagement in group activities, such as those provided by cooperative learning, need to begin at the preschool level so students are prepared for ongoing participation in their own education. Opportunities to make meaningful contributions to classroom activities and IEP meetings need to be prioritized and scaffolded as needed.

While cooperative learning groups foster self-determination for students via opportunities for self-evaluation and leadership, they also allow students to establish positive social interdependence, though teachers have to decide how to structure and intervene when challenges inevitably occur (Baloche \& Brody, 2017). For instance, students may not be equally contributing to a task. This could be due to a lack of skills or experience related to collaboration, differential social status, or limited communication skills (Le, Janssen, $\&$ Wubbels, 2018). Together, general and special educators (and other service providers) need to address these concerns. To better facilitate collaboration between students with and without disabilities, students need to learn about respecting differences and how to problem solve. Teachers can help model these processes and skills. Though academic progress is, of course, one of the main objectives of cooperative learning, the value of cooperation in and of itself should not be overlooked. Disability activist, Mia Mingus (2010), has identified interdependence as a key principle of disability justice. It is never too early to begin sharing the principles of collaboration and interdependence with students.

To avoid the student with a disability becoming dependent on another student or adult, cooperative learning groups should be structured so each student has a role Johnson \& Johnson, 2008). For students with disabilities to be successful in cooperative learning groups and to be active participants, students may need to receive individualized accommodations and modifications. According to Johnson and Johnson (1999), three types of cooperative learning groups include formal, informal, and cooperative base groups. Teachers need to establish set roles and guidelines for the various responsibilities so students can be successful (King, 2008). In addition, teachers should adjust their own roles when they observe the groups and be intentional in how and when they intervene (Johnson \& Johnson, 2008). Accessible Spaces

Recommendations for how to encourage a collaborative classroom include providing an accessible environment. As
IEP teams collaboratively recommend and plan for inclusive environments, they should consider how access occurs (Olson, Leko, \& Roberts, 2016). If a paraprofessional or a classroom assistant is assigned to a student, the teacher should assign adults to rotate around the room and monitor the student while encouraging and allowing for as much independence and interdependence in and among students as possible (Carter \& Kennedy, 2006).

A thriving example that portrays all three collaborative relationships between educators, educators and parents, and students is the journey of a young man named Alex. Crystal, one of the authors of this article, can personally account to the importance and success a fully included student with disabilities can have and the importance of collaboration at all levels and times. Alex, a 21-year-old who has the label of autism, is successfully enrolled in his fourth year in one of Southern California's public universities. Alex was initially diagnosed with autism at age 4 and was considered within the severe range of the spectrum by their local school district and Regional Center, a private nonprofit organization which coordinates and provides community-based services to people with developmental disabilities in California. Alex began speaking when he was about six and a half years old, and struggled with control over his stereotypy, a repetitive or ritualistic movement, posture, or utterance. In addition, he struggled with changes to his routine, visual and auditory stimulation, and remaining seated when expected by his teachers. Yet, he seemed to have an intense interest in academics and appeared to retain what he was learning. Alex began his schooling in a segregated special education class. When he was 7 years old, Crystal asked the school to place Alex in a general education classroom with special education supports. Initially, Crystal received some pushback from educators, administrators, and even some parents of other students. However, with the support of her case manager from the Regional Center, they placed Alex in a general education classroom with support. Crystal and her son definitely had their successes and challenges in Alex's inclusive journey through the public-school system. In the end, Alex and Crystal found more willing participants and collaborators in their journey. Collaboration among the general education teacher, special education teacher, and related service providers became much more important when Alex became fully included in general education settings. Crystal expressed to the educational professionals her concern for Alex missing vital instructional time. The providers needed to determine the amount of times Alex would be pulled out for occupational therapy, adaptive physical education, and language and speech services. Their resolution after collaborating was to push in Alex's classroom and have some afterschool sessions. The push in settings also allowed Alex's general education teacher and one-to-one assistant an opportunity to observe and replicate the techniques the providers were using with Alex. This was one of many collaborative decisions between Alex's general education teacher, special education teacher, and related service providers that helped him succeed academically and socially.

Collaboration between Alex's parent and his teachers were key throughout his public-school career. Because the majority of his teachers did not have a special education background, many times Crystal was their resource not only as a special educator but also as Alex's mother. Most educators were open to ideas and suggestions concerning Alex, all having his best interest in mind. In other instances, Alex's parent and his teachers collaborated in searching for ideas on how to best create opportunities for him to socialize. In elementary school, this included using his one to one assistant in organized play scenarios at lunch and recess and also having the one to one assistant lead small group instruction with other students besides Alex. In high school, this included having Alex assigned to the football team as the 
videographer and participating in weightlifting with footbal team members. Alex's parent and his teachers had the best collaborative experience when they exercised mutual respect and being active listeners.

Collaboration between students, peers, and educators was the most meaningful to Alex during his high school years. Alex created meaningful and long-lasting friendships with his typical peers early on with the supports of his one-to-one assistant. These relationships followed him through to high school and beyond. Alex's peers were supportive through social events at his high school, defending him when necessary, and by remaining in contact with him now as seniors in college. Both Alex's peers and their parents agree Alex was not the only one who benefitted from their friendship-they also gained socially and emotionally by Alex being in their lives.

When his high school journey ended, Alex expressed some very positive experiences and memories such as being crowned freshman homecoming prince, being the high school football team videographer, successfully passing several advanced placement courses, and walking across the stage with the top 50 students to receive their high school diplomas. Alex is currently in his fourth year as a university student maintaining a 3.0 GPA with supports in place from the Office for Students With Disabilities and other social services agencies. He will be graduating with his bachelor's degree at the end of this academic year and is applying for a master's degree program. He has also been an advocate and guest speaker in elementary schools and university classes since he was 12 years old to educate and advocate for those who, like him, have a disability. Not every child will have the same outcome, but if the appropriate opportunities are not offered based on an individual's needs, we are limiting growth and denying students the chance to meet their highest potentials.

\section{Summary}

Collaboration among and between all stakeholders is critical in the design and delivery of inclusive education. Building respectful collaborative relationships that reflect integrity, effective communication, and supporting one another is an essential ingredient for inclusive education to be effective. Inclusive education is considered a research-based best practice service delivery model for students with and without disabilities. Collaboration is one of the key essential elements to ensure effective inclusive education.

\section{References}

Allport, G. W. (1954). The nature of prejudice. Reading, MA: Addison-Wesley.

Baloche, L., \& Brody, C. M. (2017). Cooperative learning: Exploring challenges, crafting innovations. Journal of Education for Teaching: International Research and Pedagogy, 43, 274-283. doi:10.1080/02607476.2017.1319513

Beninghof, A. M. (2012). Co-teaching that works: Structures and strategies for maximizing student learning. Indianapolis, IN: Jossey-Bass.

Blanchard, K., Ripley, J., \& Paisi-Carew, E. (2015). Collaboration begins with you. Oakland, CA: Barrett-Kohler.

Blue-Banning, M., Summers, J., Frankland, H. C., Lord Nelson, L., \& Beegle, G. (2004). Dimensions of family and professional partnerships: Constructive guidelines for collaboration. Exceptional Children, 70, 167-184. doi:10.1177/001440290407000203
Cameron, L., \& Rutland, A. (2008). An integrative approach to changing children's intergroup attitudes. In S. R. Levy (Ed.), Intergroup attitudes and relations in childhood through Adulthood (pp. 191-203). New York, NY: Oxford University Press.

Carter, E. W., \& Kennedy, C. H. (2006). Promoting access to the general curriculum using peer support strategies. Research and Practice for Persons With Severe Disabilities, 31, 284-292. doi:10.1177/154079690603100402

Carter, N., Prater, M. A., Jackson, A., \& Marchant, M. (2010). Educators' perceptions of collaborative planning processes for students with disabilities. Preventing School Failure: Alternative Education for Children and Youth, 54, 60-70. doi:10.3200/PSFL.54.1.60-70

Conroy, P. W. (2012). Collaborating with cultural and linguistically diverse families of students in rural schools who receive special education services. Rural Special Education Quarterly, 31, 24-28. doi:10.1177/875687051203100304

Conderman, G. (2018). Establishing parity in middle and secondary co-taught classrooms. The Clearing House: A Journal of Education Strategies, Issues and Ideas, 91, 222228. doi:10.1080/00098655.2018.1524358

Delano, M. E., Keefe, L., \& Perner, D. (2008). Personnel preparation: Recurring challenges and the need for action to ensure access to general education. Research and Practice for Persons With Severe Disabilities, 34, 232-240. doi:10.2511/rpsd.33.4.232

De Boer, A., Pijl, S. J., \& Minnaert, A. (2012). Students' attitudes towards peers with disabilities: A review of the literature. International Journal of Disability, Development and Education, 59, 379-392. doi:10.1080/103491 2X.2012.723944

Endrew F. v. Douglas County School District RE-1, 137 S. Ct. 988 (2017).

Falvey, M. A. (2005). Believe in my child with special needs. Baltimore, MD: Brookes.

Fish, W. W. (2006). Perceptions of parents of students with autism towards the IEP meeting: A case study of one family support group chapter. Education, 127, 56-68. doi:10.3200/PSFL.53.1.8-14

Friend, M., \& Cook, L. (2013). Interactions: Collaboration skills for school professionals (7th ed.). Boston, MA: Pearson.

Friend, M., Cook, L., Hurley-Chamberlain, D., \& Shamberger, C. (2010). Co-teaching: An illustration of the complexity of collaboration in special education. Journal of Educational and Psychological Consultation, 20, 9-27. doi:10.1080/10474410903535380

Hagelman, E. (2013). Spccial education co-teachers' perceptions: Collaboration, involvement in instruction and satisfaction. University of New Orleans Theses and Dissertations. 1741.

Individuals with Disabilities Education Act (2004). Sec. 300.321. IEP Team. Retrieved from https://sites.ed.gov/idea/ regs/b/d/300.321

Individuals with Disabilities Education Act (2004). Sec. 300.34 Related services. Retrieved from https://sites.ed.gov/ idea/regs/b/a/300.34 
Johnson, D. W., \& Johnson, R. T. (1975). Cooperative learning: The power of positive goal interdependence. University of Minnesota.

Johnson, D. W., \& Johnson, R. T. (1989). Cooperation and competition: Theory and research. Bloomington, IN: Interaction Book.

Johnson, D. W., \& Johnson, R. T. (1999). Making cooperative learning work. Theory Into Practice, 38, 67-73. doi:10.1080/00405849909543834

Johnson, D. W., \& Johnson, R. T. (2008). Social interdependence theory and cooperative learning: The teacher's role. In R. Gillies, A. Ashman, \& J. Terwel (Eds.), The teacher's role in implementing cooperative learning in the classroom (pp. 10-37). New York, NY: Springer.

Kagan, S. (1992). Cooperative learning. San Juan Capistrano, CA: Resources for Teachers.

Kalambouka, A., Farrell, P., Dyson, A., \& Kaplan, I. (2007). The impact of placing pupils with special education needs in mainstream schools on the achievement of their peers. Educational Research, 49, 365-382. doi:0.1080/00131880701717222

Kalyanpur, M., Harry, B., \& Skrtic, T. (2000). Equity and advocacy expectations of culturally diverse families' participation in special education. International Journal of Disability, Development and Education, 47, 119136. doi:10.1080/713671106

King, A. (2008). Structured peer interaction to promote higher-order thinking and complex learning in cooperating groups. In R. Gillies, A. Ashman, \&J. Terwel (Eds.), The teacher's role in implementing cooperative learning in the classroom (pp. 74-91). New York, NY: Springer.

King-Sears, Janney, R., \& Snell, M.E. (2015). Collaborative Teaming (3rd ed.). Baltimore, MD: Brookes.

Kurth, J., Mastergeorge, A. M., \& Paschall, K. (2016). Economic and demographic factors impacting placement of students with autism. Education and Training in Autism and Developmental Disabilities, 51, 3-12. Retrieved from https://www.jstor.org/stable/26420360

Larios, R., \& Zetlin, A. (2012). Parental involvement and participation of monolingualand bilingual Latino families during individual education program meetings. Journal of Education Research, 6, 279-298. Retrieved from https://www.jstor.org/journal/jeducresearch

Le, H., Janssen, J., \& Wubbels, T. (2018). Collaborative learning practices: Teacher and student perceived obstacles to effective student collaboration. Cambridge Journal of Education, 48, 103-122. doi:10.1080/0305 764X.2016.1259389

Lindsey, D. B., Thousand, J. S., Jew, C. L., \& Piowlski, L. R. (2017). Culturally proficient Inclusive schools: All means all! Thousand Oaks, CA: Corwin Press.

Lipsky, D., \& Gardner, A. (1989). Beyond separate education. Quality education for all. Baltimore, MD: Brookes.

Mastropieri, M. A., \& Scruggs, T. E. (2001). Promoting inclusion in secondary classrooms. Learning Disability Quarterly, 24, 265-274. doi:10.2307/1511115
McDuffie, K. A., Mastropieri, M. A., \& Scruggs, T. E. (2009). Differential effects of peer tutoring in co-taught and non-co-taught classes: Results for content learning and student-teacher interactions. Exceptional Children, 75, 493-510. doi:10.1177/001440290907500406

Mingus, M. (2010). Changing the framework: Disability justice. Resist Newsletter, 19, 1-2.

Morningstar, M. E., Shogren, K. A., Lee, H., \& Born, K. (2015). Preliminary lessons about supporting participation and learning in inclusive classrooms. Research and Practice for Persons With Severe Disabilities, 40, 192 210. doi:10.1177/1540796915594158

Morningstar, M., Kurth, J., \& Johnson, P. (2017). Examining national trends in educational placements for students with significant disabilities. Remedial and Special Education, 28, 3-12. doi:10.1177/0741932516678327

Murawski, W. W. (2006). Student outcomes in co-taught secondary English classes: How can we improve? Reading \& Writing Quarterly, 22, 227-247. doi:10.1080/10573560500455703

Murawski, W. W., \& Hughes, C. E. (2010). Response to intervention, collaboration, and co-teaching: A logical combination for successful systematic change. Preventing School Failure: Alternative Education for Children and Youth, 53, 267-277. doi:10.3200/ PSFL.53.267-277

Murawski, W., \& Spencer, S. (2012). Collaborate, communicate, differentiate!: How to increase student learning in today's diverse schools. Thousand Oaks, CA: Corwin.

Murray, F. B. (2002). Why understanding the theoretical basis of cooperative learning enhances teaching success. In J. S. Thousand, R. A. Villa, \& A. I. Nevin (Eds.), Creativity \& collaborative learning: The practical guide to empowering students, teachers, and families (pp. 175-180). Baltimore, MD: Brookes.

Nowicki, E. A., \& Sandieson, R. (2002). A meta-analysis of school-age children's attitudes towards persons with physical or intellectual disabilities. International Journal of Disability, Development and Education, 49, 243-265. doi:10.1080/1034912022000007270

O'Brien, J., \& Mount, B. (2015). Pathfinders: People with developmental disabilities and their allies building communities that work better for everybody. Toronto, Ontario, Canada: Inclusion Press.

Olson, A., Leko, M. M., \& Roberts, C. A. (2016). Providing students with severe disabilities access to the general education curriculum. Research and Practice for Persons With Severe Disabilities, 41, 143-157. doi:10.1177/1540796916651975

Owens, J. (2015). Exploring the critiques of the social model of disability: The transformative possibility of Arendt's notion of power. Sociology of Health \& IIIness, 37, 385-403. doi:10.1111/1467-9566.12199

Perez, C. M. (2017). Empowering Latino parents: Advocating for elementary aged children with autism spectrum disor$\operatorname{der}(A S D)$ (Doctoral dissertation). Retrieved from ProQuest Dissertations and Theses database. (Order No. 10280061) 
Pijl, S. J. (2005). Interventions for social integration: Training of social skills for students with disabilities in regu lar education (in Dutch). In B. F. van der Meulen, C. Vlaskamp, \& K. C. van den Bos (Eds.), Interventions in special needs education (pp. 122-135). Rotterdam, The Netherlands: Lemniscaat B.V.

Remen, R. N. (1999). Helping, fixing or serving? Retrieved from https://www.uc.edu/content/dam/uc/honors/docs/ communityengagement/HelpingFixingServing.pdf

Rillotta, F., \& Nettelbeck, T. E. D. (2007). Effects of an awareness program on attitudes of students without an intellectual disability towards persons with an intellectual disability. Journal of intellectual and developmental disability, 32, 19-27. doi:10.1080/13668250701194042

Scorgie, K. (2015). Ambiguous belonging and the challenge of inclusion: Parent perspectives on school membership. Emotional and Behavioural Difficulties, 20, 35-50. doi:10 .1080/13632752.2014.947098

Shogren, K. A., McCart, A. B., Lyon, K. J., \& Sailor, W. S. (2015). All means all. Research \& Practice for Persons With Severe Disabilities, 40, 173-191. doi:10.1177/1540796915586191

Slavin, R. (1983). When does cooperative learning increase student achievement? Psychological Bulletin, 94, 429-445.

Staples, K. E., \& Diliberto, J. A. (2010). Guidelines for successful parent involvement: Working with parents of students with disabilities. TEACHING Exceptional Children, 42, 5863. doi:10.1177/004005991004200607

Thousand, J. S., Villa, R. A., \& Nevin, A. I. (2002). Creativity and collaborative learning: The practical guide to empowering students, teachers, and families. Baltimore, MD: Brookes.

Trainor, A. A. (2010). Educators' expectations of parent participation: The role of cultural and social capital. Multiple Voices for Ethnically Diverse Exceptional Learners, 12, 3350. doi:10.5555/muvo.12.2.01×3497585xtw067

Tremblay, P. (2013). Comparative outcomes of two instructional models for students with learning disabilities: Inclusion with co-teaching and solo-taught special education. Journal of Research in Special Educational Needs, 13, 251-258. doi:10.1111/j.1471-3802.2012.01270.x

United Nations. (2006). Convention of the rights of persons with disabilities and optional protocol. Retrieved from https://www.un.org/development/desa/disabilities/ convention-on-the-rights-of-persons-with-disabilities. html

U.S. Department of Education. (2010). Free appropriate public education for students with disabilities: Requirements under section 504 of the Rehabilitation Act of 1973 Retrieved from https://www2.ed.gov/about/offices/ list/ocr/docs/edlite-FAPE504.html

Valle, J. W. (2011). Down the rabbit hole: A commentary about research on parents and special education. Learning Disability Quarterly, 34, 183-190. doi:10.1177/0731948711417555

Villa, R. A., Thousand, J. S., \& Nevin, A. (2010). Collaborating with students in instruction and decision-making. Thousand Oaks, CA: Corwin Press.
Walther-Thomas, C. S. (1997). Co-teaching experiences: The benefits and problems that teachers and principals report over time. Journal of Learning Disabilities, 30, 395407. doi:10.1177/002221949703000406

Weichel, W.A. (2001). An analysis of student outcomes on cotaught settings in comparison to other special educaton service delivery options for students with learning disabilities. Dissertation Abstracts international, 62(07),2386 (UMI No. 3021407)

Zaretsky, L. (2004). Advocacy and administration: From conflict to collaboration. Journal of Educational Administration 42, 270-286. doi:10.1108/09578230410525649

Zak, P. J. (2017). The neuroscience of trust. Harvard Business Review. Retrieved from https://hbr.org/2017/01/the-neuroscience-of-trust 